\title{
Method for efficient transfection of in vitro-transcribed mRNA into SK-N-AS and HEK293 cells: Difference in the toxicity of nuclear EGFP compared to cytoplasmic EGFP
}

\author{
KATARINA EJESKÄR ${ }^{1,2}$, SUSANNE FRANSSON ${ }^{2}$, FATEN ZAIBAK $^{1}$ and PANAYIOTIS A. IOANNOU ${ }^{1}$ \\ ${ }^{1}$ Murdoch Children's Research Institute, Melbourne University, Royal Children's Hospital, 3052 Parkville, VIC, Australia; \\ ${ }^{2}$ Department of Clinical Genetics, Göteborg University, SU/Östra, SE-416 85 Gothenburg, Sweden
}

Received December 2, 2005; Accepted January 20, 2006

\begin{abstract}
Here we report a method for efficient transfection of in vitro-transcribed mRNA into two different types of human adherent cells, the neuroblastoma cell line SK-N-AS, and the transformed kidney cell line HEK293. By using newly trypsinized adherent cells in suspension and Lipofectamine ${ }^{\mathrm{TM}}$ 2000 , we detected a transfection efficiency of $80-90 \%$ in both cell lines and a cell viability of $90 \%$ in SK-N-AS and $60 \%$ in HEK293, $24 \mathrm{~h}$ after transfection when using cytoplasmic enhanced green fluorescent protein (EGFP)-mRNA. We have evaluated the different effects of the generally used EGFP that mainly localizes to the cytoplasm and nuclear EGFP, where the nuclear EGFP are more toxic to the cells than the cytoplasmic EGFP. In order to develop a null experiment, we constructed a short non-functional mRNA including a nuclear localization signal and evaluated the concentrations at which mRNA encoding nuclear proteins can be added without a general toxicity, depending on the fact that the proteins are localized to the nucleus. For both SK-N-AS and HEK293 cells, a concentration of up to $100 \mathrm{ng}$ mRNA in $10^{5}$ cells, encoding a nuclear protein with no other function, did not affect the cells. For evaluation of the method, we screened four different human mRNAs, PDG, DFFA, CORT and PEX14, for their ability to affect cell proliferation in these cells. PEX14 was the only gene that significantly $(\mathrm{p}=0.03)$ reduced cell proliferation for both cell types, DFFA significantly $(\mathrm{p}=0.04)$ reduced cell proliferation in SK-N-AS but not in HEK293 cells. $P G D$ and CORT did not have any effect on cell proliferation. We have developed an easy method for efficient delivery of in vitro-transcribed mRNA into the adherent cell lines, SK$\mathrm{N}-\mathrm{AS}$ and HEK293. This method is useful for a quick screening of how different genes affect cell proliferation.
\end{abstract}

Correspondence to: Dr Katarina Ejeskär, Department of Clinical Genetics, Göteborg University, Sahlgrenska University Hospital/East, SE-416 85 Gothenburg, Sweden

E-mail: katarina.ejeskar@clingen.gu.se

Key words: transfection, in vitro mRNA, SK-N-AS, HEK293, enhanced green fluorescent protein, nuclear localization signal, cell proliferation assay

\section{Introduction}

A major challenge today is to analyze the functions of many genes at the cellular level (1). It is possible to conduct highthroughput screening through transfectional microarrays (2) but, for many research groups, this is not an option because it requires costly equipment and, for many research projects, it might not be necessary to test thousands of genes.

The major issue in functional gene studies in living cells is good transfection efficiency, and there are numerous different methods for DNA/RNA delivery available, all with advantages and drawbacks (3). Every cell type seems to prefer different methods for effective transfection, and it also depends on the size of the DNA or RNA-molecule that the study aims to deliver. One widely used method is delivery by cationic lipids, for which, again, a wide range of different compounds is available, all with different qualities $(4,5)$. Lipofectamine ${ }^{\mathrm{TM}}$ 2000 (Invitrogen) is a widely used cationic lipid that has been shown to be an effective transfection agent for both DNA and RNA delivery (6). Easy and robust follow-up methodology and good and reliable null-function tests for comparison of experiments is also important.

Many transfection protocols are based on the use of cDNAexpression vectors; with promoters depending on the cells own transcription machinery. The transfected cDNA-vector often has an uneven distribution between cells, resulting in substantial variation in the level of delivered gene product in each cell. This might partly be due to the very strong promoters used in these vectors, thus the difference in copy number in each cell does not need to be very large to result in a major difference in the gene product produced. Another obstacle in DNA-expression vector delivery is the need for the transfected DNA to enter the nucleus for gene transcription, and this is the main difficulty in obtaining high DNA-transfection efficiency $(7,8)$. One way to overrule these problems is to use in vitro-transcribed mRNA, since this does not need to enter the nucleus in order to be translated into protein $(9,10)$. In vitro mRNA transfection has also been shown to have a high transfection efficiency and low toxicity in a number of different cell types, including embryonic stem cells and Tcells $(11,12)$.

One common way to detect and calculate transfection efficiency is to use an easily detected gene product, and one 
of the easiest and most widely used is green fluorescent protein (GFP) (13). In order to obtain a more precise detection, we used enhanced green florescent protein (EGFP), which is a unique GFP variant which contains chromophore mutations that make the protein 35 times brighter than wild-type GFP and is codon-optimized for higher expression in mammalian cells (14).

A nuclear localization signal (NLS) is a peptide sequence that forces the protein (or DNA) into the nucleus (15). There are many different types of NLS; in this study, we have used SV40-NLS (MVPKKKRKVED).

In order to evaluate the method with human gene products, we have used four different mRNAs (PDG, DFFA, CORT and $P E X 14)$, all mapped to the same region on chromosome 1p (1p36.2) (16-19). PGD (6-phosphogluconate dehydrogenase) is an enzyme in the pentose phosphate shunt. DFFA (DNA fragmentation factor $45 \mathrm{kDa} \alpha$ ) is a substrate for caspase-3 and triggers DNA fragmentation during apoptosis, it is a cytosolic protein that relocates to the nucleus when activated (20). CORT (cortistatin precursor) is a secreted neuropeptide that belongs to the somatostatin family (21). PEX14 (peroxisomal biogenesis factor 14) is a protein bound to the peroxisomal membrane, importing PTS1-containing proteins to the peroxisome $(22,23)$, it has also been shown to interact with nuclear factor erythroid-2 (NFE2) to inhibit transcriptional activation (19).

In this report, we present a method to effectively transfect in vitro-transcribed mRNA into the widely used human embryonic kidney cell line, HEK293, known to function as a good transient expression system (24), and the human neuroblastoma cell line, SK-N-AS. We also present data on the major difference in sensitivity to nuclear EGFP and cytoplasmic EGFP in these cells. In order to evaluate the effect of nuclear proteins, we developed a small non-functional peptide including a nuclear localization signal (NLS) for use in null experiments. For evaluation of the method, we screened four different human mRNAs (PDG, DFFA, CORT and PEX14) for their ability to affect cell proliferation in these cells.

\section{Materials and methods}

In vitro $m R N A$. DNA fragments of the coding region of the EGFP-gene linked to the Sp6 promoter sequence and a polyA tail at the end of the fragment was constructed by PCR using the NLS-EGFP forward primer 5'-ATTTAGGTGACACTAT AGAAGTGCGCCACCATGGTTCCGAAGAAAAAACGT AAAGTTGAGGATCCGATGGTGAGCAAGGGCGAGG-3' and NLS-EGFP reverse primer 5'-GG(T) $)_{30}$ CAGCGAGCTCT AGGGCCGC-3' for NLS-EGFP mRNA (nuclear); and the NLS-EGFP forward primer and NLS-nonsense reverse primer 5'-GG(T) ${ }_{30}$ CGACCAGGATGGGCACTTACCCGGTGAAC AGC-3' for the nonsense-NLS PCR product; using pIRESEGFP-vector as a template. PCR was performed using $\mathrm{Hi}$ Fidelity Taq (Roche) according to the supplier's protocol with an annealing temperature of $58^{\circ} \mathrm{C}$ and 25 cycles of PCR. Cytoplasmic EGFP-mRNA was produced using an EcoRIdigested Sp6-EGFP-vector as template in the in vitro mRNA reaction.

Full-length IMAGE cDNA clones of the genes, DFFA (GenBank: BC000037), PEX14 (GenBank: BC006327), and
PGD (GenBank: BC000368) (HGMP Resource Centre, UK), and a clone for CORT (GenBank: AF013252) (Incyte Genomics, Palo Alto, CA) were used as templates to make a full-length PCR product. DNA fragments containing the coding region of the genes linked to the Sp6 promoter sequence and a polyA tail at the end of the fragment was constructed by PCR using gene specific primers with the Sp6-sequence (ATTTAGGTGACACTATAGAAGTG) added to the forward primer, and a poly $(\mathrm{T})_{30}$ to the reverse primer. Primer sequences are available upon request.

The PCR product (500 ng) was used as a template for in vitro mRNA using mMESSAGE mMachine (Ambion). The procedure was according to supplier's protocol using 4-h incubation at $37^{\circ} \mathrm{C}$. The mRNA was DnaseI-treated for $15 \mathrm{~min}$ at $37^{\circ} \mathrm{C}$ and LiCl-precipitated. The concentration of mRNA was measured by spectrophotometry while integrity and length was evaluated by agarose gel electrophoresis.

Tissue culture. The neuroblastoma cell line, SK-N-AS (ECACC), and the kidney derived cell line, HEK293 (ATCC), were cultured in Dulbecco's modified Eagle's medium (DMEM) with $10 \%$ fetal calf serum (FCS) supplemented with L-glutamine, at $37^{\circ} \mathrm{C}$ using standard procedures. One day before any transfection experiment the cell lines were split into new culture flasks; cells with $60-80 \%$ confluence were used in transfection experiments.

Immediately before the transfection procedure, the cells were trypsinized and washed twice with PBS and the viable cell numbers were calculated using trypan blue staining.

Transfection of $m R N A$. Transfection was performed on newly trypsinized cells in suspension in a 12-well plate, using $2 \times 10^{5}$ cells/well in $1 \mathrm{ml}$ DMEM with $10 \% \mathrm{FCS} /$ well for SK-N-AS and $10^{5}$ cells for HEK293. For each transfection, different amounts of mRNA (Fig. 3) and $1 \mu 1$ Lipofectamine ${ }^{\mathrm{TM}} 2000$ (Invitrogen) were used. The mRNA and the Lipofectamine 2000 were incubated for $30 \mathrm{~min}$ in $100 \mu \mathrm{l}$ OPTI-MEM (Gibco) before being added to the cell suspensions. The cell and Lipofectamine 2000-mRNA complex mix were immediately divided into 96-well plates, at $10^{4}$ cells/well for SK-N-AS and $5 \times 10^{3}$ cells/well for HEK 293 and incubated at $37^{\circ} \mathrm{C}$ for $5 \mathrm{~h}$ before an extra $50 \mu 1 /$ well DMEM with $10 \%$ FCS was added. At $24 \mathrm{~h}$ after transfection, the transfection efficiency was evaluated using fluorescence microscopy, by estimating the number of EGFP-expressing cells (green) (Fig. 1).

Cell growth assay. After transfection, the cells were divided into 96-well plates. Cells with each different construct were divided into 4 wells/plate, in 3 different plates with $10^{4}$ cells in $100 \mu 1$ DMEM $10 \%$ FCS per well. The cells were incubated for 1-3 days at $37^{\circ} \mathrm{C}$; one plate was used every day for 3 days after transfection to monitor cell growth. Twenty $\mu 1$ of CellTiter96 Aqueous One Solution (Cell Proliferation Assay, Promega, Madison, WI) was added to each well and incubated in a humid dark chamber at $37^{\circ} \mathrm{C}$ for $2-4 \mathrm{~h}$. The absorbance was detected at $490 \mathrm{~nm}$ by an ELISA-reader (Labsystems Multiscan RC). The results were compared to a standard curve to calculate the number of live cells per well each day. The mean number of cells in the 4 wells evaluated per day per construct was used in evaluating the results. 

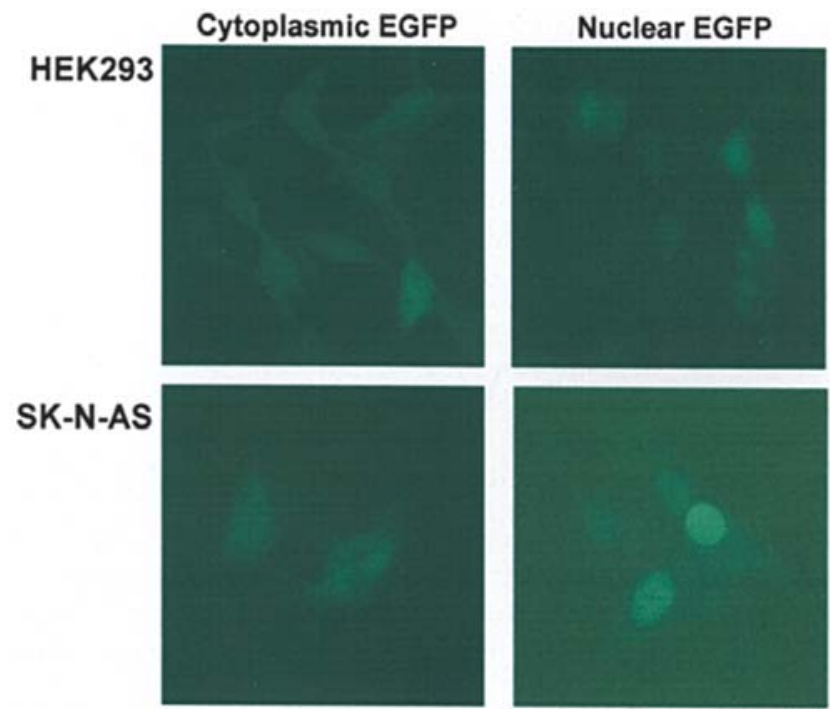

Figure 1. Cells transfected with $1 \mu \mathrm{g}$ of cytoplasmic EGFP or nuclear EGFP in $10^{5}$ HEK 293 cells or $2 \times 10^{5}$ SK-N-AS cells. By fluorescent microscopy, it is possible to detect the difference in localization of EGFP in the cytoplasm (left panels), or in the nucleus (right panels).

Experiments comparing different mRNA and mRNAconcentrations were performed from the same batch of cells and treated equally throughout the experimental procedure.

\section{Results and discussion}

The transfection efficiency of EGFP-mRNA, using Lipofectamine 2000 , for both cell lines was $80-90 \%$ as determined by fluorescence microscopy $24 \mathrm{~h}$ after transfection. By cell counting, we determined the average cell viability to $89 \%$ in EGFP-transfected SK-N-AS cells compared to untreated cells $24 \mathrm{~h}$ after transfection. For HEK293 cells, this number was $59 \%$. Thus, HEK293 cells were more sensitive to this treatment. By fluorescence microscopy, we also detected a clear difference in the cytoplasmic EGFP-mRNA and the nuclear NLS-EGFP-mRNA transfections; in the NLS-EGFP transfections, the nucleus was clearly stained green, whereas the generally used EGFP showed an even green stain in the entire cell (Fig. 1). This proves that the nuclear localization signal (NLS) is working.

In order to be able to functionally screen genes in cell lines, full-length in vitro-transcribed mRNA can be created for each gene. The use of mRNA instead of expression cDNA vectors results in both an increase in the transfection efficiency and eliminates the need for cloning. This is a relatively easy way to functionally test genes where the fulllength cDNA construct is not available, with the exception of very large genes which could have a problem providing good PCR-product yields.

We detected a major difference in cell toxicity between cytoplasmic EGFP, the EGFP generally used, and an EGFP molecule that we constructed including a nuclear localization signal (NLS), nuclear EGFP. In both cell types, we detected an approximate 6-fold difference in the number of viable cells $48 \mathrm{~h}$ after transfection when $1 \mu \mathrm{g}$ mRNA of EGFP respectively NLS-EGFP was used, with the nuclear NLS-EGFP showing lower cell growth (Fig. 2). This was an intriguing
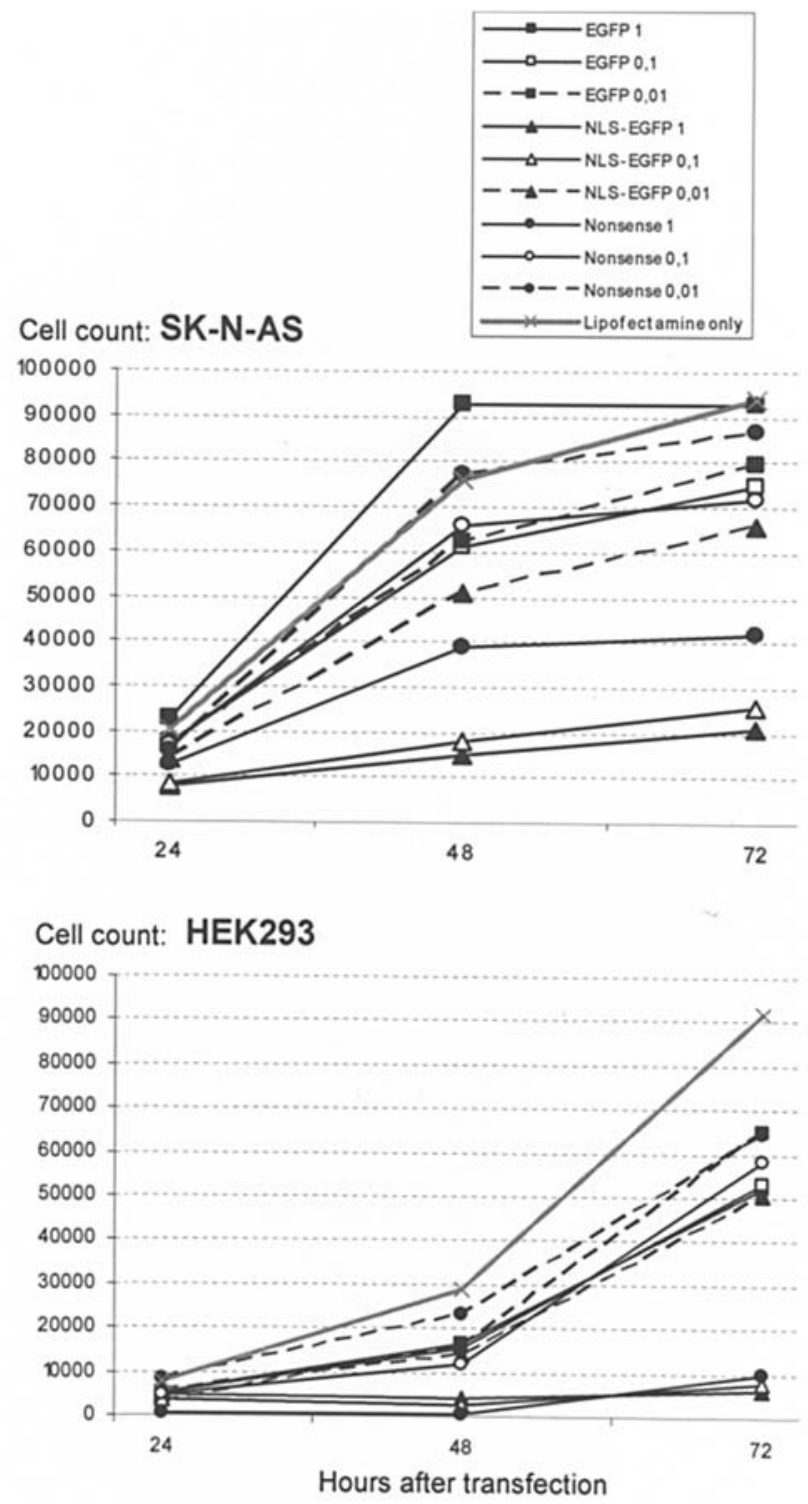

Figure 2. Cell growth curves of transfected SK-N-AS cells (at the top) and HEK293 cells (at the bottom). Three different concentrations $(1,0.1,0.01 \mu \mathrm{g}$ per $2 \times 10^{5}$ cells) for three different mRNAs: cytoplasmic EGFP (EGFP), nuclear EGFP (NLS-EGFP) and a non-sense-NLS-construct (Nonsense), and a Lipofectamine 2000-only control with no mRNA (Lipofectamine only). Viable cells were counted 24,48 and $72 \mathrm{~h}$ after transfection.

finding, indicating that these cells were more sensitive to EGFP located in the nucleus than to EGFP in the cytoplasm. The cytoplasmic EGFP, on the other hand, did not seem to affect the cell viability to any extent. In order to eliminate this difference between cytoplasmic and nuclear EGFP, the mRNA-concentration needed to be very low: $10 \mathrm{ng}$ in $2 \times 10^{5}$ cells. This was the same for both SK-N-AS and HEK293 cells (Fig. 3). It is questionable whether these very low concentrations are effective, since the Lipofectamine-only control showed the same results as the experiments with mRNA (Figs. 2 and 3).

In order to use this method for functional evaluation of nuclear proteins, we found the need to develop a molecule that would have a nuclear localization but not such a devastating effect on cell viability as NLS-EGFP. We constructed mRNA with the same NLS-sequence (MVPKKKRKVED) as NLS- 


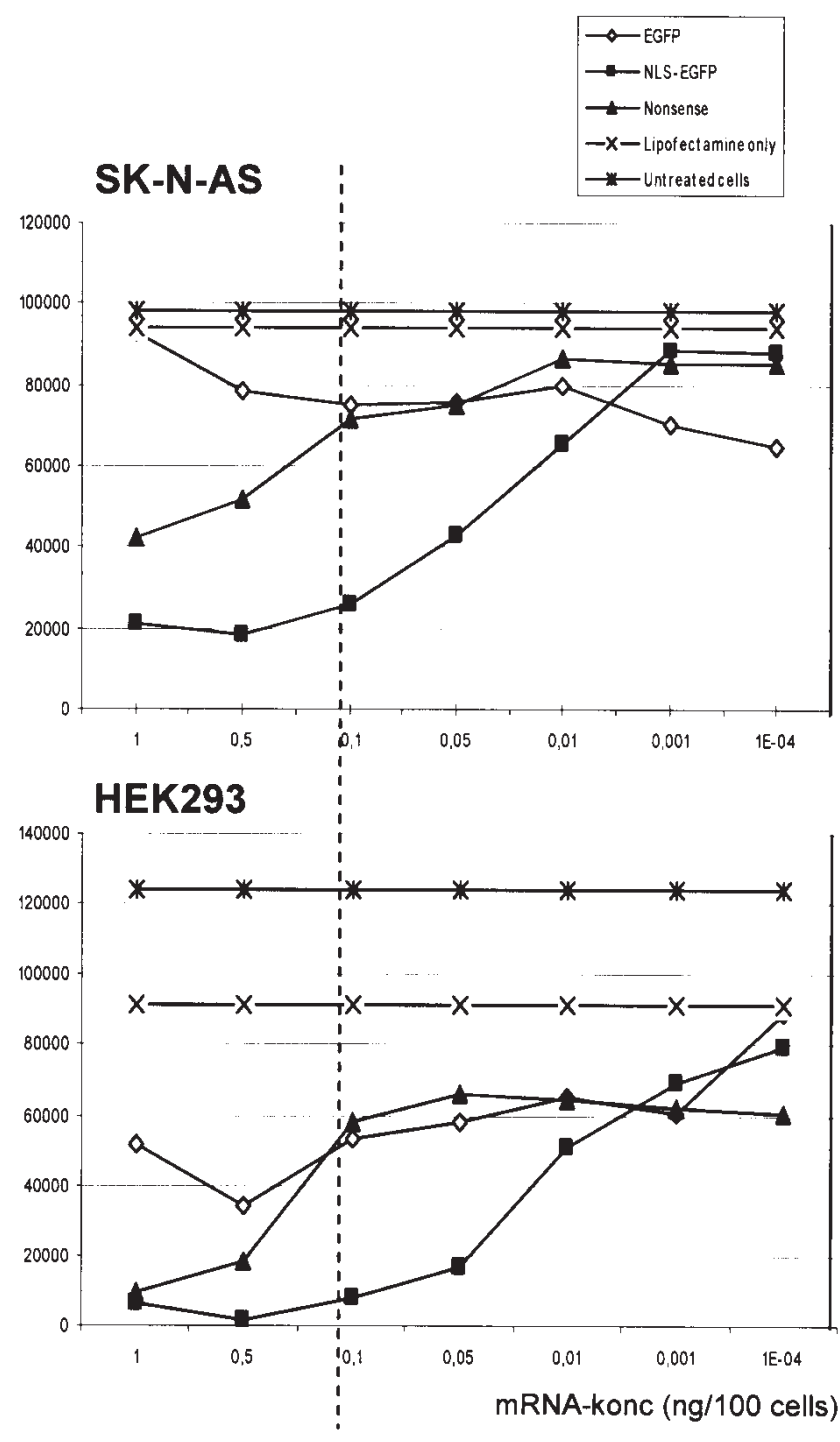

Figure 3. Number of viable SK-N-AS cells (at the top) and HEK293 cells (at the bottom) $72 \mathrm{~h}$ after transfection of different concentrations of in vitrotranscribed mRNA, indicated on the $\mathrm{x}$-axis (at ng per $10^{2}$ cells). Three different mRNAs have been used: cytoplasmic EGFP (EGFP), nuclear EGFP (NLSEGFP) and a nonsense-NLS-construct (Nonsense), Lipofectamine 2000only control with no mRNA (Lipofectamine only), and untreated cells. The mRNA-concentration where cytoplasmic EGFP-treated cells and nonsenseNLS-treated cells are equally affected is indicated with a dotted line.

EGFP but with a short truncated peptide (PMVSKGEELFTG) added to the NLS-peptide. In order to easily compare the different mRNA-constructs, we used the same EGFP-vector (pIRES-EGFP) as a base in the construction of the nonsenseNLS-construct.

We detected a difference in cell viability after transfection of cytoplasmic EGFP, NLS-EGFP and the nonsense-NLSconstruct. The nonsense-mRNA was more toxic to the cells than the cytoplasmic EGFP but less toxic than NLS-EGFP, as expected; the higher the mRNA-concentration, the larger the difference in cell growth after transfection (Fig. 3). A cutoff concentration, where the nonsense-NLS-construct did not have a more negative effect on cell viability than cytoplasmic EGFP had, was evaluated to approximately $100 \mathrm{ng} / 10^{5}$ cells for both cell types (Fig. 3). HEK293 cells were generally more sensitive to this treatment than SK-N-AS cells were,

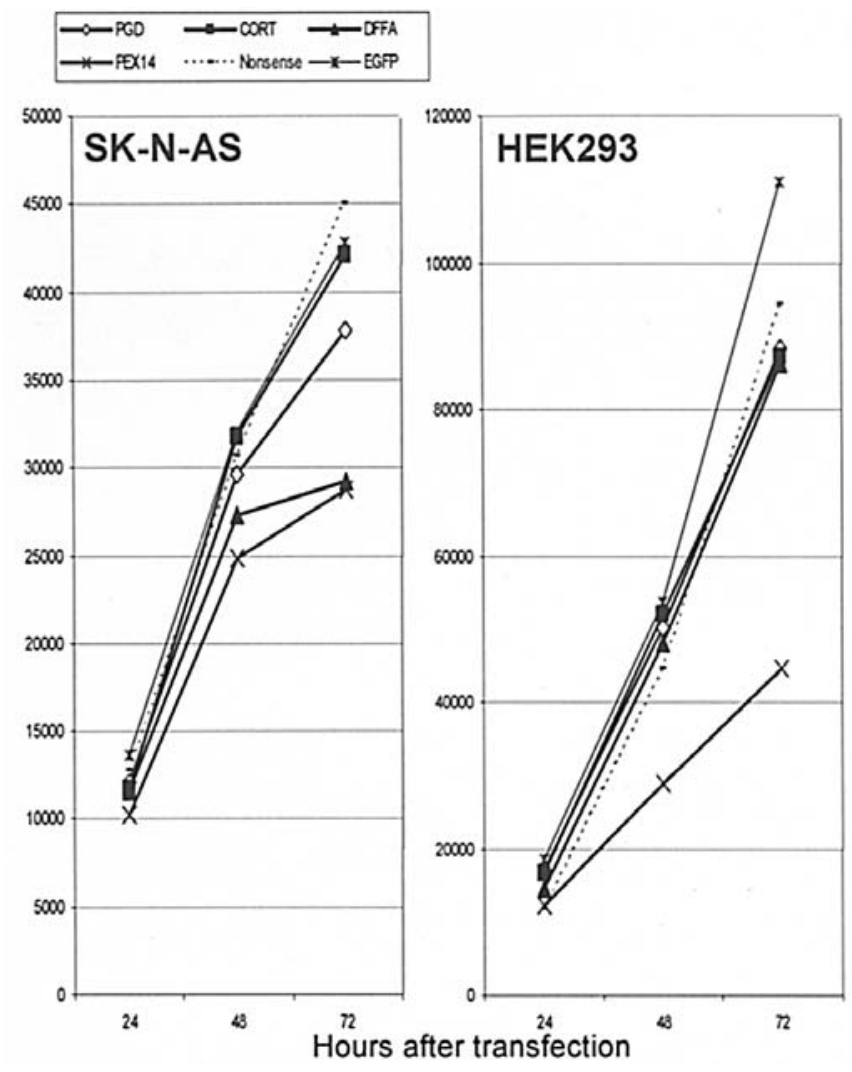

Figure 4. Cell growth curves of transfected SK-N-AS (left) and HEK293 cells (right), transfected with six different in vitro mRNAs: PGD, CORT, DFFA, $P E X 14$, Non-sense and $E G F P$ at $0.1 \mathrm{ng} / 10^{2}$ cells. Viable cells were counted 24,48 and $72 \mathrm{~h}$ after transfection. PEX14 significantly $(\mathrm{p}=0.03)$ reduces cell proliferation in both cell lines and $D F F A$ significantly $(\mathrm{p}=0.04)$ reduces cell proliferation in SK-N-AS cells compared to the Nonsense experiment, whereas $P G D$ and CORT do not have any significant effect.

but the cut-off concentration was the same per cell for both cell types.

In order to evaluate the method, we used four known human mRNAs encoding proteins with different functions and cell localization. All four genes are localized to the same chromosomal region, 1p36.2, a region that is hemizygously deleted in SK-N-AS cells (25) but not in HEK293 cells. One of the genes, PEX14, had a significant reduction in cell proliferation 48-72 h after transfection in both cell lines (Table I, Fig. 4). Pex14 is a peroxisomal protein $(22,23)$ that also includes a nuclear localization signal and can inhibit transcriptional activation (19). Whether the effect on cell proliferation in these cells is due to the specific activity of this gene needs further investigation. DFFA had an effect on cell proliferation in the $1 \mathrm{p}$ deleted cell line, SK-N-AS, but not in HEK293 cells (Table I, Fig. 4). DFF45, a gene product of $D F F A$, is a cytosolic protein that needs to be activated by caspase- 3 to trigger DNA fragmentation during apoptosis (20). The effect of DFFA is dependent on the status of caspase- 3 in the cells, which might differ between SK-N-AS and HEK293 cells. Also, the fact that SK-N-AS cells have lost one copy of this gene could explain the difference in effect on cell proliferation between SK-N-AS and HEK293 cells. The other two genes, PGD and CORT, did not have any effect on cell proliferation (Table I, Fig. 4). $P G D$ encodes an enzyme in the pentose phosphate shunt, and CORT encodes Cortistatin, a hormone-like neuropeptide (21); neither 
Table I. Effects of in vitro-transcribed mRNA (100 ng/105 cells) on cell proliferation after transfection into SK-N-AS and HEK293 cell lines, compared to non-sense-mRNA. ${ }^{\mathrm{a}}$

\begin{tabular}{|c|c|c|c|c|c|}
\hline \multirow[b]{2}{*}{ mRNA } & \multirow[b]{2}{*}{$\begin{array}{l}\text { Hours after } \\
\text { transfection }\end{array}$} & \multicolumn{2}{|l|}{ SK-N-AS } & \multicolumn{2}{|l|}{ HEK293 } \\
\hline & & $\begin{array}{l}\% \text { difference in average number of } \\
\text { cells compared to nonsense-mRNA }\end{array}$ & $\begin{array}{l}\text { p-value } \\
\text { t-test }\end{array}$ & $\begin{array}{l}\% \text { difference in average number of } \\
\text { cells compared to nonsense-mRNA }\end{array}$ & $\begin{array}{c}\text { p-value } \\
\text { t-test }\end{array}$ \\
\hline \multirow{3}{*}{$P G D$} & 24 & -5 & $\mathrm{~ns}$ & 45 & 0.02 \\
\hline & 48 & -3 & $\mathrm{~ns}$ & 13 & ns \\
\hline & 72 & -16 & $\mathrm{~ns}$ & -6 & $\mathrm{~ns}$ \\
\hline \multirow{3}{*}{$C O R T$} & 24 & -8 & ns & 42 & 0.02 \\
\hline & 48 & 4 & $\mathrm{~ns}$ & 17 & $\mathrm{~ns}$ \\
\hline & 72 & -6 & $\mathrm{~ns}$ & -7 & $\mathrm{~ns}$ \\
\hline \multirow{3}{*}{$D F F A$} & 24 & -9 & ns & 23 & ns \\
\hline & 48 & -11 & 0.02 & 8 & ns \\
\hline & 72 & -35 & 0.04 & -8 & $\mathrm{~ns}$ \\
\hline \multirow{3}{*}{ PEX14 } & 24 & -20 & ns & 4 & ns \\
\hline & 48 & -19 & 0.04 & -35 & 0.03 \\
\hline & 72 & -36 & 0.03 & -53 & 0.0005 \\
\hline
\end{tabular}

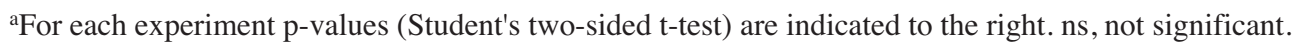

of these two proteins are nuclear. These results show a difference in cell proliferation between different genes using this method. Further investigations are needed to prove that these effects are due to the specific activity of the genes in question and not to the cellular localization of the gene products.

This method is robust and the results are reproducible and show the same differences between different constructs if the experiment is repeated. This method is relatively easy to use, and no special equipment is needed, except a tissue cultureand a PCR-facility; equipment that most laboratories have. The method can be used to evaluate how different genes affect cell viability, and we believe that the nonsense-NLS-construct can generally be used as a control, even though the best control will always be a mutated null-function variant of the gene that is tested.

By using newly trypsinized cells in suspension and Lipofectamine 2000, we obtained a transfection efficiency of in vitro-transcribed mRNA of $80-90 \%$ in both SK-N-AS and HEK293 cells. We also evaluated the different effects of cytoplasmic EGFP and nuclear EGFP, where the nuclear EGFP is significantly more toxic to the cells compared to the cytoplasmic EGFP. In order to develop a null experiment for functional tests of nuclear proteins, we constructed a short non-functional mRNA including an NLS, and evaluated the concentrations at which mRNA encoding nuclear proteins can be added without general toxicity, depending on the fact that the proteins are localized to the nucleus. This method is relatively easy and possible for most laboratories since no special equipment is required.

\section{Acknowledgements}

We gratefully acknowledge the financial support of the Swedish Cancer Society, the Children's Cancer Foundation, the King Gustav V Jubilee Clinic Cancer Research Foundation, the Assar Gabrielsson Foundation, Svenska Läkaresällskapet and Lars Hiertas Minne. The work was also partially supported by a grant from the Brockhoff Foundation to P.I.

\section{References}

1. Tyers M and Mann M: From genomics to proteomics. Nature 422: 193-197, 2003

2. Carpenter AE and Sabatini DM: Systematic genome-wide screens of gene function. Nat Rev Genet 5: 11-22, 2004.

3. Recillas-Targa F: Gene transfer and expression in mammalian cell lines and transgenic animals. Methods Mol Biol 267: 417-433, 2004.

4. Elouahabi A and Ruysschaert JM: Formation and intracellular trafficking of lipoplexes and polyplexes. Mol Ther 11: 336-347, 2005

5. Uchida E, Mizuguchi H, Ishii-Watabe A and Hayakawa T: Comparison of the efficiency and safety of non-viral vectormediated gene transfer into a wide range of human cells. Biol Pharm Bull 25: 891-897, 2002.

6. Gitlin L, Karelsky S and Andino R: Short interfering RNA confers intracellular antiviral immunity in human cells. Nature 418: 430-434, 2002.

7. Lechardeur D, Sohn KJ, Haardt M, Joshi PB, Monck M, Graham RW, Beatty B, Squire J, O'Brodovich H and Lukacs GL: Metabolic instability of plasmid DNA in the cytosol: a potential barrier to gene transfer. Gene Ther 6: 482-497, 1999.

8. Lukacs GL, Haggie P, Seksek O, Lechardeur D, Freedman N and Verkman AS: Size-dependent DNA mobility in cytoplasm and nucleus. J Biol Chem 275: 1625-1629, 2000.

9. Malone RW, Felgner PL and Verma IM: Cationic liposomemediated RNA transfection. Proc Natl Acad Sci USA 86: 6077-6081, 1989.

10. Bettinger T, Carlisle RC, Read ML, Ogris M and Seymour LW: Peptide-mediated RNA delivery: a novel approach for enhanced transfection of primary and post-mitotic cells. Nucleic Acids Res 29: 3882-3891, 2001

11. Ponsaerts $\mathrm{P}$, van der Sar S, van Tendeloo VF, Jorens PG, Berneman ZN and Singh PB: Highly efficient mRNA-based gene transfer in feeder-free cultured $\mathrm{H} 9$ human embryonic stem cells. Cloning Stem Cells 6: 211-216, 2004

12. Smits E, Ponsaerts P, Lenjou M, Nijs G, van Bockstaele DR, Berneman ZN and van Tendeloo VF: RNA-based gene transfer for adult stem cells and T cells. Leukemia 18: 1898-1902, 2004. 
13. Chalfie M, Tu Y, Euskirchen G, Ward WW and Prasher DC: Green fluorescent protein as a marker for gene expression. Science 263: 802-805, 1994.

14. Zhang G, Gurtu V and Kain SR: An enhanced green fluorescent protein allows sensitive detection of gene transfer in mammalian cells. Biochem Biophys Res Commun 227: 707-711, 1996.

15. Zanta MA, Belguise-Valladier P and Behr JP: Gene delivery: a single nuclear localization signal peptide is sufficient to carry DNA to the cell nucleus. Proc Natl Acad Sci USA 96: 91-96, 1999.

16. Douglas GR, McAlpine PJ and Hamerton JL: Regional localization of loci for human PGM and 6PGD on human chromosome one by use of hybrids of Chinese hamster-human somatic cells. Proc Natl Acad Sci USA 70: 2737-2740, 1973.

17. Ejeskar K, Abel F, Sjoberg R, Backstrom J, Kogner P and Martinsson T: Fine mapping of the human preprocortistatin gene (CORT) to neuroblastoma consensus deletion region $1 \mathrm{p} 36.3 \rightarrow \mathrm{p} 36.2$, but absence of mutations in primary tumors. Cytogenet Cell Genet 89: 62-66, 2000.

18. Leek JP, Carr IM, Bell SM, Markham AF and Lench NJ: Assignment of the DNA fragmentation factor gene (DFFA) to human chromosome bands $1 \mathrm{p} 36.3 \rightarrow \mathrm{p} 36.2$ by in situ hybridization. Cytogenet Cell Genet 79: 212-213,1997.

19. Gavva NR, Wen SC, Daftari P, Moniwa M, Yang WM, YangFeng LP, Seto E, Davie JR and Shen CK: NAPP2, a peroxisomal membrane protein, is also a transcriptional corepressor. Genomics 79: 423-431, 2002 .
20. Liu X, Zou H, Slaughter C and Wang X: DFF, a heterodimeric protein that functions downstream of caspase-3 to trigger DNA fragmentation during apoptosis. Cell 89: 175-184, 1997.

21. De Lecea L, Criado JR, Prospero-Garcia O, Gautvik KM, Schweitzer P, Danielson PE, Dunlop CL, Siggins GR, Henriksen SJ and Sutcliffe JG: A cortical neuropeptide with neuronal depressant and sleep-modulating properties. Nature 381: 242-245, 1996.

22. Albertini M, Rehling P, Erdmann R, Girzalsky W, Kiel JA, Veenhuis M and Kunau WH: Pex14p, a peroxisomal membrane protein binding both receptors of the two PTS-dependent import pathways. Cell 89: 83-92, 1997.

23. Will GK, Soukupova M, Hong X, Erdmann KS, Kiel JA, Dodt G, Kunau WH and Erdmann R: Identification and characterization of the human orthologue of yeast Pex14p. Mol Cell Biol 19: 2265-2277, 1999.

24. Thomas P and Smart TG: HEK293 cell line: a vehicle for the expression of recombinant proteins. J Pharmacol Toxicol Methods 51: 187-200, 2005.

25. Van Roy N, Jauch A, van Gele M, Laureys G, Versteeg R, De Paepe A, Cremer T and Speleman F: Comparative genomic hybridization analysis of human neuroblastomas: detection of distal $1 \mathrm{p}$ deletions and further molecular genetic characterization of neuroblastoma cell lines. Cancer Genet Cytogenet 97: 135-142, 1997. 